\title{
Recent Challenges and Methodologies in Smart Grid Demand Side Management: State-of-the-Art Literature Review
}

\author{
Tehreem Nasir, ${ }^{1}$ Syed Sabir Hussain Bukhari ${ }^{2},{ }^{2,3}$ Safdar Raza ${ }^{(D)}{ }^{1}$ \\ Hafiz Mudassir Munir $\mathbb{D D}^{2}{ }^{2}$ Muhammad Abrar, ${ }^{4}$ Hafiz Abd ul Muqeet, ${ }^{5}$ \\ Kamran Liaquat Bhatti $\mathbb{D}^{1},{ }^{1}$ Jong-Suk Ro $\mathbb{D}^{\mathbb{B}},{ }^{3,6}$ and Rooha Masroor ${ }^{1}$ \\ ${ }^{1}$ Department of Electrical Engineering, NFC Institute of Engineering and Technology, Multan, Pakistan \\ ${ }^{2}$ Department of Electrical Engineering, Sukkur IBA University, Sukkur 65200, Pakistan \\ ${ }^{3}$ School of Electrical and Electronics Engineering, Chung-Ang University, Seoul 06974, Republic of Korea \\ ${ }^{4}$ Department of Electrical Engineering, Bahauddin Zakariya University, Multan, Pakistan \\ ${ }^{5}$ Department of Electrical Engineering, Punjab Tianjin University of Technology, Lahore 54770, Pakistan \\ ${ }^{6}$ Department of Intelligent Energy and Industry, Chung-Ang University, Seoul 06974, Republic of Korea \\ Correspondence should be addressed to Jong-Suk Ro; jongsukro@gmail.com
}

Received 10 June 2021; Revised 8 July 2021; Accepted 30 July 2021; Published 9 August 2021

Academic Editor: Qiuye Sun

Copyright ( 2021 Tehreem Nasir et al. This is an open access article distributed under the Creative Commons Attribution License, which permits unrestricted use, distribution, and reproduction in any medium, provided the original work is properly cited.

\begin{abstract}
The concept of smart grid was introduced a decade ago. Demand side management (DSM) is one of the crucial aspects of smart grid that provides users with the opportunity to optimize their load usage pattern to fill the gap between energy supply and demand and reduce the peak to average ratio (PAR), thus resulting in energy and economic efficiency ultimately. The application of DSM programs is lucrative for both utility and consumers. Utilities can implement DSM programs to improve the system power quality, power reliability, system efficiency, and energy efficiency, while consumers can experience energy savings, reduction in peak demand, and improvement of system load profile, and they can also maximize usage of renewable energy resources (RERs). In this paper, some of the strategies of DSM including peak shaving and load scheduling are highlighted. Furthermore, the implementation of numerous optimization techniques on DSM is reviewed.
\end{abstract}

\section{Introduction}

With the growing energy demand over the course of time, it has become essential to utilize energy efficiently. DSM is a significant feature of the smart grid; it can be defined as a set of techniques that can be used to modify the consumption pattern of the end users of electricity over time. DSM methods encourage the users to optimize their energy usage and focus on reducing the energy cost and improving the efficiency. DSM not only benefits the consumers by reducing their energy bills, but also benefits the energy systems or utilities through shifting the load from peak to non-peak hours.

Energy consumption patterns at consumers' premises vary throughout the day depending on users' activities. The generating capacity must be able to fulfill the energy demand in peak periods. DSM actions are used in smart grid to manage load profile of the end users for efficient utilization of generated power.

Over time, more concern is being paid to the demand side rather than modifying the generating side of the power system to fill the gap between the energy supply and demand. The conventional grid faces challenges in supporting developing technologies, integrating renewable energy resources, and DSM. Smart grid overcomes the challenges faced by the conventional electricity gird as it supports the emerging technologies, renewable energy resources, distributed generation (DG), energy storage systems (ESS), smart meters, and future electricity needs.

Smart grid technology involves interaction between utility, customers, and control centers. Electricity suppliers can modify the energy consumption pattern on the 
consumer side through proper implementation of DSM. In [1], the possibility of existence of more than one utility on the supplier side is addressed. The DSM program to tackle the peak load demand induced by the residential customers in smart grid with multiple suppliers is modeled as two noncooperative games, the supplier side game and the customer side game. The supplier side game aims to maximize the supplier's profit. The suppliers send their bids to the DSM center, where energy price is calculated and is sent to the customers. In the second game, the customer aims to determine the optimal load profile to maximize their daily payoff. The two games are played simultaneously, and there exist a unique Nash equilibrium for both games.

A model consisting of three layers, utility in the first layer, demand response aggregator in the second layer, and consumers in the third layer, is proposed in [2] for achieving hierarchical day-ahead DSM. The utility aims to minimize operational cost, DR aggregator aims to maximize net benefit, and consumers aim to minimize their electricity bills. A multiobjective problem is formulated to achieve these objectives that are solved using artificial immune algorithm.

A method is proposed in [3] that would help the energy divisions predict the residential energy dynamic pattern for demand and supply management and specify a reference for making decisions on power allocation. Considering an entire region consisting of 16000 residential buildings, first, the data are classified, and then energy consumption patterns are discovered. Afterwards, particle swarm optimization $\mathrm{K}$-means algorithm is employed for clustering analysis, and then an efficient model is proposed using support vector machine, and its practicality is proved. The results showed that the proposed method will improve the overall quality of power grid.

The concept of liberalized energy market is taken into consideration in [4], where authors suggest an "intersupplier cooperation mechanism" between users for DSM in low voltage networks. For each consumer, the authors apply the network costs and the commodity costs to reach a global optimum. The energy consumption schedule (ECS) is defined by decentralized optimization algorithm for flexible appliances through smart meters by each user. A fair distribution of cost is achieved among users through the proposed approach upon reaching the Nash equilibrium. In [5], the authors have developed a fully distributed and independent DSM framework that can track the drifts from changes in consumer preferences and energy pricing coming from energy markets. The consumers can maximize their satisfaction level without relying on global information. The utility has no need to take part in the proposed algorithm for minimizing the grid total payment. The proposed framework minimizes consumer's incommodity, utility's grid total payment, and the total peak to average ratio.

The generating capacity must be able to fulfill the energy demand in peak periods. DSM programs can be used to overcome the insufficient electricity generation. A bottling company in Nigeria was considered as a case study in [6]. Application of DSM on industrial load showed an increase in load factor by 7.45 percent and decrease in peak demand by 8.44 percent and yearly end user saving of 4.18 percent. The study adopted a mathematical algorithm for this purpose. The challenges faced by power utilities with the ever-increasing energy demand can be reduced through the application of dynamic thermal rating (DTR) system and DSM methods [7]. The authors focus on the study of the reliability of the transmission network through investigating several DSM methods and their interaction with the application of DTR system.

To improve the effectiveness of DSM for all consumers, detailed consumption data of all consumers is required. With the development of "advanced metering infrastructure (AMI)," consumption data of all consumers can be collected by the utilities, and various DSM programs can be developed depending on the data characteristics. In [8], the potential of commercial consumers for participation in DSM applications based on data obtained through smart meters is analyzed and studied. The problems associated with smart meter data size, complexity, and variability for utilization in load forecasting and DSM schemes are addressed in [9]. A new clustering-based approach is proposed for analysis of smart meters. The objective is focused at providing optimal DSM solutions, more accurate load profile, improved load forecasting, and reducing load profile complexity. The proposed approach deals with data volatility and complexity by linearizing the load profiles and reducing errors.

The previous approaches on DSM have not considered the states of other distribution network components. In [10], the authors try to overcome the deficiencies in existing DSM methods by considering all the components in the grid as hierarchical agents. Exchange of info among various hierarchical levels is based on joint intention protocol. The authors emphasize a communication protocol specification for properly managing the energy demand management in various hierarchical agents.

A multitimescale DSM scheduling approach, considering the day-ahead and week-ahead scheduling, is proposed in [11]. Various DSM techniques appropriate for distinct day-ahead and week-ahead timeframes coordinate to give the optimal scheduling in entire timeframe. A dynamic scenario generation method is proposed to control the load uncertainty in the week-ahead scheduling. In multitimescale DSM scheduling, the functionality can be achieved successfully by considering the priorities of various DSM methods and the willingness of participants.

The authors tried to clear some uncertainties in the most cited autonomous demand side management (A-DSM) algorithm in [12]. In a DSM algorithm, Nash equilibrium (NE) is not unique, but it forms a convex set of NEs. Its convergence depends on consumers taking turns in it. With large number of consumers, convergence rate will be slow. In this paper, the authors propose that the consumers take decisions in parallel. The proposed algorithm increases the convergence rate for a large no of consumers, with a small increase in system cost.

This paper presents an extensive literature on DSM optimization techniques. The layout of the paper is shown in Figure 1. Section 2 describes the categorization of DSM methods. Section 3 provides a brief review on DSM 


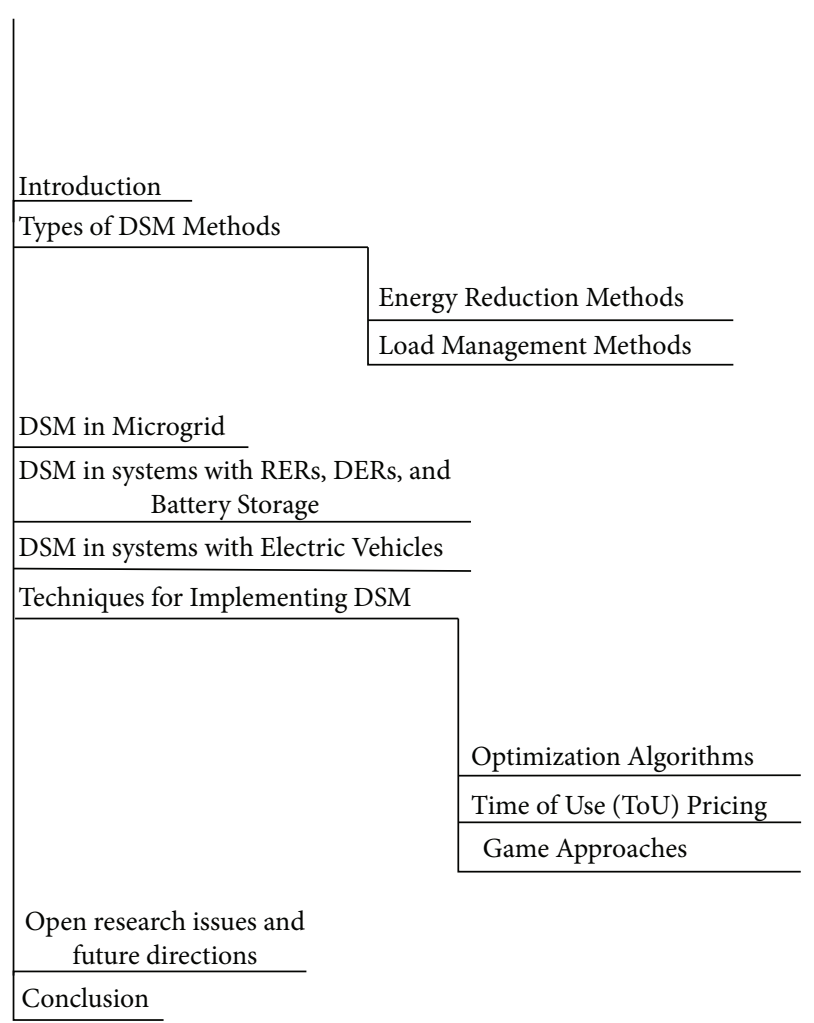

Figure 1: Layout of the paper.

application in microgrid. Sections 4 and 5 discuss the impact of DSM in systems with integrated RERs, DERs, battery storage, and EVs, respectively. Section 6 provides a comprehensive survey on various optimization techniques for DSM implementation. Section 7 discusses the research issues and presents future research directions. Section 8 concludes the survey.

\section{Types of DSM Methods}

DSM measures are taken by utilities or the end users themselves. Utilities make efforts to persuade consumers to modify their demand patterns by introducing positive tariff incentives. It will permit the users to shift their demand activities at times that will minimize their electricity costs and also help utilities by shifting the demand away from peak periods. The users can either directly reduce their energy consumption or move their demand activities to the periods of low peaks to reduce the bills. The types of DSM methods can be classified into the following categories:

(i) Energy reduction methods

(ii) Load management methods

The DSM methods focus on reducing the energy consumption cost, minimizing the peak demand, improving the peak to average ratio, minimizing the user discomfort through modification in operating patterns of the devices, and increasing consumption of energy obtained through local generation sources.
The major objectives of demand side management are stated below:

(i) Electricity cost minimization

(ii) Minimize customer discomfort

(iii) Maximize usage of local energy generation

(iv) Minimize peak demand

(v) Minimize peak to average ratio

Figure 2 shows the taxonomy of optimization objectives of DSM.

2.1. Energy Reduction Methods. This category covers a wide range of suitable measures that can be adopted to reduce power consumption in all sectors. Figure 3 indicates some energy-saving tips.

An optimization technique has been proposed in [13] for nonflexible load demand management in smart grid for academic buildings. The optimization mechanism uses a fuzzy controller and integer linear programming technique. The proposed mechanism makes decision on human like thinking to control the operation of nonflexible loads based on convenience level affected by individual appliances. The goal is to minimize overall power consumption by optimizing nonflexible load without disturbing user comfort. The work focused on minimizing the energy consumption in academic buildings as given in the following equation:

$$
\min _{s_{i}} \sum_{s_{i}}^{N}\left(1-\frac{\lambda_{i} C_{i}}{P_{i}} s_{i}\right)
$$

where $s_{i}$ represents the switch control for appliance $i$ in a set of appliances, and $P_{i}$ and $C_{i}$ represent the power consumption at any specific instant and the convenience level of any particular appliance $i$ in a set of appliances, respectively.

The potential of energy-saving behavior as a cost effective and efficient DSM strategy for developing countries like Bangladesh is investigated in [14]. The results showed that the consideration of the energy-saving behavior as a demand response policy at the consumer side along with the previously developed DSM plan in Bangladesh reduces the energy demand by 50.7 percent. For solving the DSM challenge in home area networks (HANs), the authors in [15] propose "real-time multiagent deep reinforcement learning based approach." The proposed approach updates the system every day based on learning the preference of appliance utilization along with considering the consumer's behavior for avoiding any discomfort.

An energy management algorithm for controlling the temperature settings and energy supply to the heating and ventilation systems in residential buildings is proposed in [16].

The proposed energy management system is intended to achieve optimal price, energy supply, and temperature setting. Moreover, the impact of price oscillations on the proposed algorithm is also studied. In [17], a "home energy management system (HEMS)" participating in a DSM program provided with an edge computing server for 


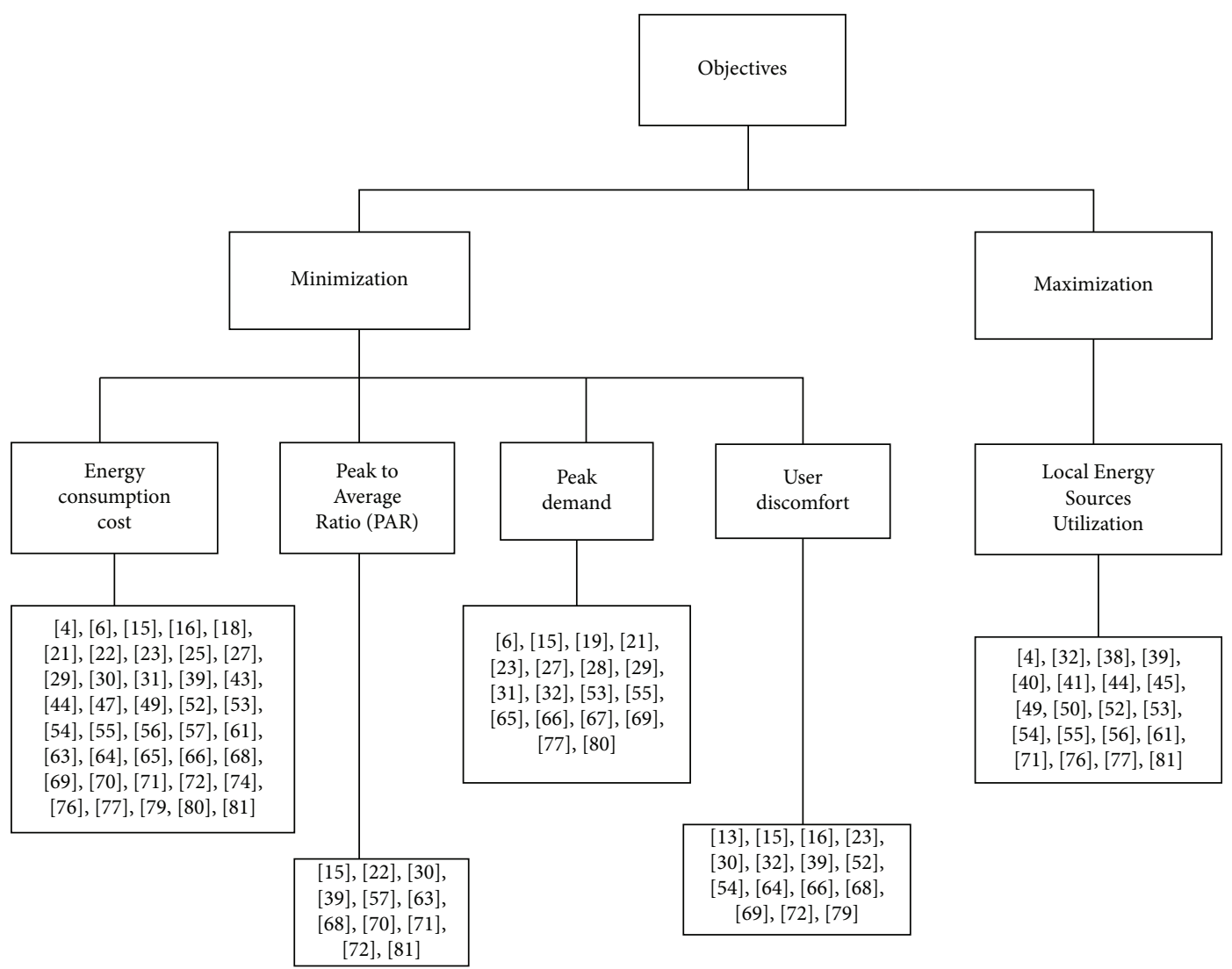

FIgURE 2: Optimization objectives of DSM.

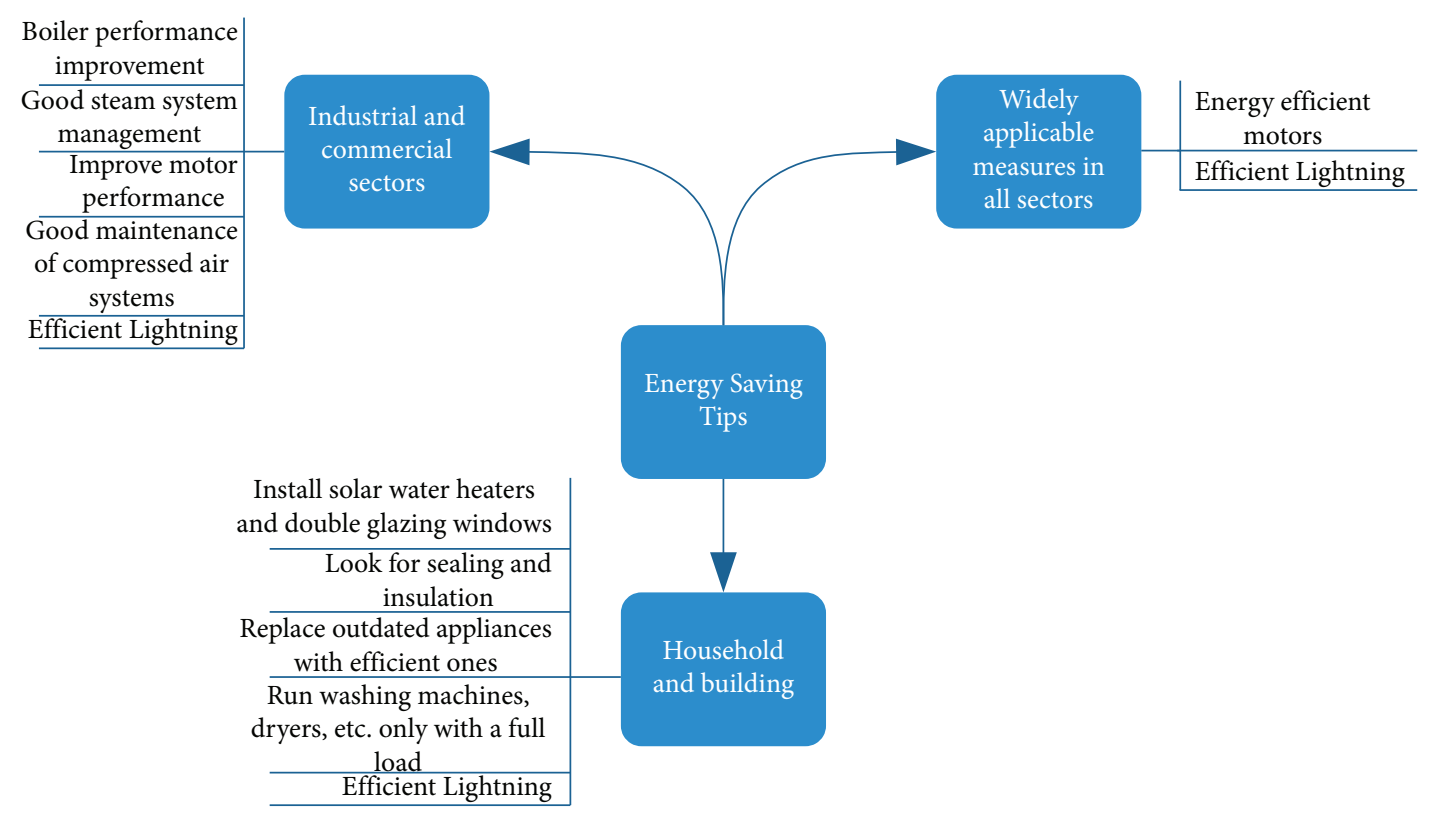

FIgURE 3: Energy-saving tips.

maximizing the expected total reward of the homeowner is inspected. The DSM strategy considered in this paper encourages reducing the household energy consumption in particular timeframe. Deep reinforcement learning is used to solve this problem. User's decision making problem is formulated as a "Markov decision process (MDP)," and the 
objective is aimed at finding the optimal policy $\pi^{*}$ from the MDP that will maximize the expected total reward $\mathbb{E}$ as given in the following equation:

$$
\pi^{*}=\arg \max _{\pi \varepsilon \Pi_{M}} \mathbb{E}^{x}\left[\sum_{t=1}^{\infty} \gamma^{t} \mu(s(t), a(t))\right] .
$$

A DSM technique is presented in [18] to enhance the effectiveness of street lighting system. The authors justify that employing the effective energy devices like "individual Lighting Device Control (ILDC), Centralize Control Monitoring System (CCMS) and Light Emitting Diodes (LEDs), etc." can result in energy consumptions' savings, reducing maximum demand and carbon dioxide. For analyzing the DSM system, street lighting system is simulated in DIALux evo 7.1 software. Moreover, equipment is monitored by means of an application named "CM DASHBOARD". In [19], the authors justify that controlling the power consumption of a commercial refrigeration system results in reduction of overall peak demand and in turn reduces the energy cost. Temporary adjustments in refrigeration system energy demand can be performed by the implemented control approach considering the temperature limits of stored items and air. Control performance can be increased by an additional dynamic reference adjustment approach.

2.2. Load Management Methods. The actions performed to adjust and control the load instead of power supply on a network for achieving the balance between electricity supply and the load are known as load management methods. Electricity cost and load patterns are closely related to each other. The variations in load pattern can help reduce electricity cost, which is one of the major goals of DSM. Variations in load pattern fall into six categories as shown in Figure 4 [20]. The techniques mentioned in the Figure 4 are used to achieve load management and DSM.

Peak clipping is the process of reducing demand during peak demand periods. It mainly focuses on the reduction of peak demand. Valley filling is the process of filling valleys (periods of low demand) to improve the system load factor. In load shifting, the loads are shifted from peak periods to off-peak periods.

Strategic conservation is the reduction in load caused by a decrease in overall energy consumption utilizing energy efficient appliances or measures that minimize consumers' energy needs. Strategic load growth refers to an increase in load caused by an increase in overall energy consumption, aimed at increasing electricity sales.

Back Tracking Search Algorithm (BSA) is proposed in [21] to minimize peak load demand and total utility cost for three types of customers: residential, customer, and industrial. The proposed algorithm is an improved version of Differential evolution (DE). The comparison of simulation results with results obtained from Particle Swarm Optimization (PSO) algorithm shows the effectiveness of BSA in terms of peak load reduction, cost effectiveness, and handling many different types of devices. In [22], the authors present the DSM strategies and propose an algorithm for multiobjective

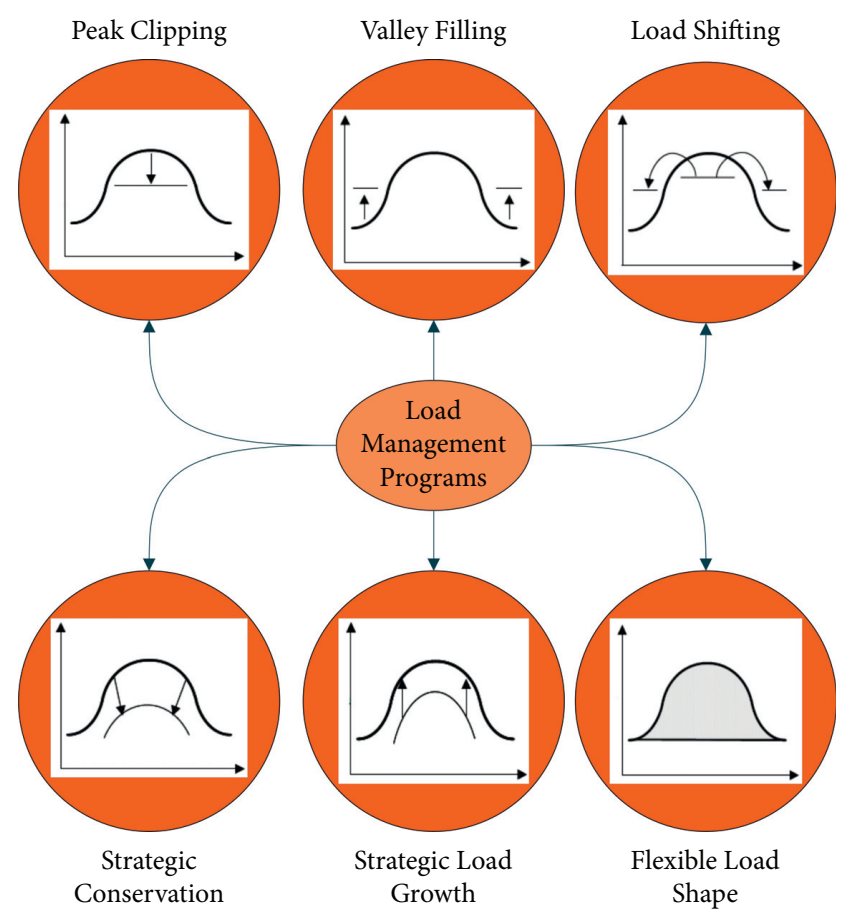

FigURE 4: Load management programs.

optimization (MOO) DSM problem for day-ahead scheduling of load. Discrete time varying model is used to determine price of energy for one day. Greedy search algorithm is used for scheduling of controllable loads. The loads considered have different values of average power and time-constrained interval for switching on. The implementation of proposed algorithm shows that all loads will be scheduled. It also shows the reduction in cost and peak to average power ratio (PAPR). The MOO problem is formulated as stated in the following equation:

$$
\min _{U_{\Delta}} \mathbf{f}\left(\mathbf{U}_{\Delta}\right)=\left[f_{1}\left(\mathbf{U}_{\Delta}\right) f_{2}\left(\mathbf{U}_{\Delta}\right)\right],
$$

where $\left(\mathbf{U}_{\Delta}\right)$ can be observed as a matrix representing equipment schedule controlled through home energy management system, the objective functions $f_{1}$ is the energy cost metric, and $f_{2}$ is the PAPR metric, and $\mathbf{f}\left(\mathbf{U}_{\Delta}\right)$ minimization indicates minimizing every vector element simultaneously.

A novel residential DSM approach utilizing a smart load control strategy based on varying power consumption limits (PCLs) on half hourly basis is proposed in [23]. The design takes into consideration the realistic loads, user's preferences, and comfort. Time of use pricing scheme is used to realize the impact of demand response on user's preferences. The results of the proposed control strategy are compared with a conventional load control strategy developed on the basis of fixed power consumption limits (PCLs). The optimization problem is expressed by the following equation:

$$
J_{\mathrm{Res}}=\sum_{t=1}^{T} P_{\mathrm{Res}}^{t} \cdot C_{\mathrm{ToU}}^{t} \cdot
$$


A DSM strategy for scheduling load over a day based on Latent Dirichlet Allocation algorithm is proposed in [24]. It uses a human-in-loop approach to shift the loads considering the probability density function of consumer's usage pattern of appliances and cost function. In [25], the major objective of DSM, i.e., cost reduction, is achieved by using the load shifting technique. For sample test, industrial load comprising of 109 appliances is tested. The test results showed that the application of load shifting technique has reduced electricity consumption cost, and the application of neural network created in MATLAB resulted in reduced value of mean square error.

A three-phase grid supportive DSM method application on distribution network is employed in [26] for scheduling of flexible loads. The major goal is to resolve the violations in operation limit effectively independent of other objectives that DSM follows. Effectiveness of the proposed approach is tested using a case study on market scheduling for reducing over and high voltages. A load management algorithm is proposed in [27] for appliance scheduling in accordance with consumer preferences and utility control for minimizing cost and peak load demand. Genetic algorithm (GA) is used to solve the optimization problem expressed in

$$
\min \sum_{k=1}^{m} C_{\mathrm{ToU}}^{t}\left[\sum_{i=1}^{N} \sum_{j=1}^{n i} P_{i j}^{t} X_{i j}^{t}\right],
$$

where $X_{i j}^{t}$ is 0 for off state and 1 for on state of the appliance.

The authors in [28] focus on limiting the peak load in residential community through the application of load shifting DSM technique. The energy consumption patterns are recorded on hourly basis for four types of loads: general load, cooling/heating, white appliances, and entertainment. The application of load shifting DSM technique resulted in a significant reduction in peak load.

The load shifting technique is used to solve the DSM problem utilizing MATLAB GUI for minimizing the peak energy demand and electricity cost in [29]. Users can calculate the total expenditure based on their energy consumption with the help of the proposed software. Using time of the day (TOD) tariff structure, the load is shifted form peak hours to non-peak hours by means of load shifting technique in this software. A load shifting DSM technique is implemented in the proposed "home energy management system (HEMS)" to manage load demand of a smart home in real-time and day-ahead basis through coordination among home appliances during peak and non-peak hours in [30]. The proposed technique is tested for three pricing schemes: time of use pricing, critical peak pricing, and real-time pricing. The purpose of the proposed technique is to reduce the energy prices and peak to average ratio without destroying consumer comfort level. A minimization problem is formulated in [31] utilizing the day-to-day load shifting method for DSM modeling, considering the user comforts. "Symbiotic organisms search (SOS) algorithm" has been employed for the optimization process. Simulation results show that the implementation of DSM using SOS algorithm presents better accuracy compared to several other algorithms in terms of peak load reduction. The objective problem is formulated as given in equation (6a). Equation (6b) gives the electricity bill over the day.

$$
\begin{aligned}
& \min \sum_{t=1}^{N=24}\left(P^{t}-\text { Target }^{t}\right)^{2}, \\
& \min J=\sum_{t=1}^{N=24} P^{t} \cdot J^{t}
\end{aligned}
$$

where Target ${ }^{t}$ is the objective curve value at instant $t$.

DSM in district heating systems (DH systems) is done by load shifting or by controlling the substation regulation strategy. A substation regulation strategy, "Differential of Return Temperatures (DRT)," is adopted for shaving thermal peaks without compromising the indoor comfort condition in [32]. Peak load shaving is the process of flattening the load curve to reduce the peak load demand by shifting the load to the lower peak periods. An extensive literature has been presented in [33] on peak shaving techniques.

The impact of DSM measures on integrated electricitygas system (IEGS) is studied in [34]. Through optimal scheduling of IEGS, reduction in the overall cost of the system consisting of investment cost, operational cost, carbon emission cost, and DSM compensation is observed. The normal operational constraints of electricity and gas systems are included for the purpose of secure operation. The objective problem is stated in

$$
\min f=\sum_{\tau=1}^{Y} \frac{J_{\mathrm{inv}}(\tau) J_{\mathrm{op}}(\tau) J_{\mathrm{dsm}}(\tau) J_{\text {carbon }}(\tau)}{(1+r)^{\tau-1}},
$$

where $\tau$ is the planning year.

A DSM strategy is proposed in [35] for managing PELs (power electronic loads) in DC distribution network to reduce the operational cost of system. In this paper, the PELs are modeled as variable resistors, and the bus voltage is derived. Then, a DSM approach is used to decide a voltage strategy that would be optimum for regulating the PELs to minimize the system cost. The objective problem is formulated as a minimization problem to determine the optimal bus voltage $\mathbf{V}^{*}$ that will minimize the cost of system.

\section{DSM in Microgrid}

Microgrid is a smart power network that can operate independently of the bulk generation. It can be connected to the power grid, where it works in synchronization with the grid, or it can operate autonomously. Microgrid supplies energy obtained through integrated distributed energy resources (DERs) to nearby users. So, it is a local form of energy. Microgrid is the future of power system, and much work is done on improving its structure and performance. Many DSM programs are also implemented for energy management in microgrid.

Impact of DSM actions on flexible loads (EVs) distributed at consumers' side in an isolated LV microgrid is studied in [36]. The purpose of this study is to evaluate the 
effect of implementation of control actions on user's side on the operation of isolated microgrid. The issue of impact of noncoordinated DSM actions on peak power, voltage drops, and energy losses in the microgrid is also addressed. Two case studies considering active and passive end users are examined. The study is carried out implementing a suitable model of the microgrid in Neplan environment, while the daily controlled load profiles of the end users are evaluated using the Monte Carlo approach implemented in MATLAB. Seven different scenarios are considered. In all scenarios, voltage drop and peak power remain within the limits, and energy loss decreases. The analysis showed that the presence of PV plant could originate energy loss. The results of the study are useful to the distributed system operators who will face all the issues rising in a fully automated environment.

A two-stage real-time demand side management (RDSM) for microgrid incorporating schedulable ability (SA) and uncertainties is proposed in [37]. An internal pricing model is proposed in first stage to minimize operation cost and to retain the power balance as given in

$$
\min J_{T_{\text {hor }}}=\min \left[J_{T_{\text {hor }, t}}+\sum_{h=1}^{T-1} \widehat{J}_{T_{\text {hor }, t+h \mid t}}\right] .
$$

For further compensation of uncertainties, a schedulable ability (SA) model and SA evaluation system is made available for response executors (REs) in the second stage. The SA evaluation system takes the real-time data and information history of REs and provides faster-time scale online allocation of power among the response executors.

A DSM method is proposed in [38] to keep the real-time demand in track with the planned day-ahead energy generation by microgrid considering consumers who predicted aggregate load demands. The consumers utilize stored energy, renewable generation, and plan strategies to charge or discharge their EVs. Consumers deviating from the predicted load demand are charged penalties.

A real-time algorithm for DSM of a microgrid integrated with renewable energy resources is developed in [39]. The algorithm optimizes the cost and maximizes the consumer's satisfaction. The solution for utility maximization has been presented aiming at the two objectives: maximizing the user and provider's satisfaction and minimizing the total cost of energy as given in equation (9). For each user $i$,

$$
\begin{aligned}
& \max \sum U(t)-J(t), \\
& \max \sum U\left(P_{j}^{t}, \omega_{j}^{t}\right)-J\left(\sum C_{p}^{t}, P_{j}^{t}\right) .
\end{aligned}
$$

Scheduling of power considering the variable loads has been employed to reduce the changes in power demand. The computation time required by complex algorithms is excluded in the proposed technique for DSM.

For managing demand and to avoid voltage fluctuations resulting from the integration of renewable energy sources in a microgrid, installation of electric spring is proposed in [40] to provide constant voltage to the critical loads instantaneously and automatically schedule the noncritical loads. Its implementation can provide voltage regulation in commercial and residential buildings. A fuzzy type-2 logic controller (FT2LC) is used for DSM of a hybrid stand-alone power system integrated with only renewable energy resources in [41]. An air conditioning system is controlled using FT2LC under uncertainty conditions. The effectiveness of the proposed controller is verified by considering three control situations. The results showed that FT2LC is suitable for controlling system considering uncertainties.

The authors in [42] implement direct load control using demand response (DR) technique along with automatic generation control to overcome the fluctuations in microgrid frequency to ensure safe operation of microgrid. The objective is centered at minimizing the frequency deviation as stated in

$$
\min \int_{0}^{\infty}(\Delta f)^{2} \mathrm{~d} t
$$

The proposed model of microgrid consists of wind power turbine generator (WTG), diesel energy generation (DG), and controllable loads like heat pumps (HP), hybrid plug in EVs (PHEV), and refrigerator (REF). The DR controllers (PID or PI) and automatic generation control (AGC) parameters are optimized using Genetic Algorithm (GA) and Firefly Algorithm (FF) for frequency regulation.

The authors present an energy management system approach for the campus microgrid $(\mu \mathrm{G})$; in this, they actually propose an optimal management and scheduling of storage in the presence of DGs, which not only contributes to reducing the consumption cost (customer), but also contributes to reducing the grid load (utility) [43]. Moreover, a demand response management (DRM) system has been proposed in [44] that will decide mutual optimal solution for both customers and utility by employing service provider. Service provider is located at different levels of power grid, lower level service provider controlling the neighborhood, and highest-level service provider controlling other service providers. The optimization problem was solved by interior-points method, followed by assessment of demand response using particle swarm optimization and artificial immune systems.

This section reviews some works done on DSM application in microgrid. The rest of the article is focused on the application of DSM in smart grid.

\section{DSM in Systems with Integrated RERs, DERs, and Storage Devices}

To cope with the increasing energy demand and to reduce the increased emission of $\mathrm{CO} 2$, energy generation from renewable energy resources has gained much importance. Various DSM techniques are applied to manage the distributed energy resources, renewable energy resources, and the storage devices, for energy efficient operation of the overall system.

The integration of renewable energy resources at consumer's premises is gaining immense popularity. A resource scheduling algorithm is proposed in [45] for efficiently using the energy generated to reduce the cost of energy consumption of individual user. A battery scheduling algorithm is proposed to select the suitable size of battery for increasing 
the savings. A case study on an electrical company in Sweden, Herrljunga Elektriska AB, is conducted in [46]. The study shows the impact of installation of wind and PV generation on DSM and distribution side operators (DSO). The results are an increase in DSM value and reduced cost of a DSO. In [47], the optimization of use of multiple residential energy resources is done using the evolutionary algorithm. The objective of the proposed approach is to minimize the electricity bills of customers and maximize the customers' comfort level, while maintaining the energy quality and reducing the peak to average ratio simultaneously. The authors take into the account the constraints coupled with thermostatically controlled loads and storage systems.

The environmental and economic impacts of DER system with multiple energy sources are reduced through optimal operation scheduling of the DER system in [48]. The optimal operation scheduling of DER is done by the proposed stochastic multiobjective linear programming model.

Interaction among all types of energy from numerous DERs has led to the creation of energy hubs. The aim of these energy hubs is the interaction among multienergy carriers through the grid. A method for optimal scheduling of multienergy hub has been proposed in [49] for minimizing the cost of energy hubs. Moreover, using energy from clean energy resources such as solar PV and windmill in the energy hubs instead of gas-fired system over the scheduling horizon has led to the reduction in greenhouse gas (GHG) emission. The combined cooling, heating, and power (CCHP) systems are used as a backup system for minimizing the load shedding for stochastic producers. Energy storage devices are also used for storing excess energy. Figure 5 shows the schematic of renewable based energy hub. Monte Carlo simulation, fast forward selection method, and demand response programs are applied on an IEEE 10-bus standard test system integrated with distributed energy systems. Simulation results showed the effectiveness of proposed method in energy management of energy hubs.

Assuming the dynamic renewable generation, energy pricing, and loads, the authors in [50] propose a real-time algorithm for joint load scheduling and energy storage control to minimize the overall system cost over a finite time, at residential side with integrated renewable energy resources. They have taken into consideration the costs and operational constraints of battery, the power requirements and service duration of individual load, and minimum/ average delay requirements.

The large magnitude of fluctuations and uncertainties due to large scale integration of renewable energy resources into power networks results in increased operational cost of power system. A method is proposed for smoothing variations in power using the demand response of a large no of residential appliances in [51]. Higher fluctuations in energy prices due to incorporation of renewable energy resources call for an increase in activation of flexible loads. In [52], the authors propose a framework for production planning and participating in the reserve markets for exploiting the economic prospective of emerging energy markets. This problem is formulated using "a multistage stochastic Mixed-
Integer Linear Programming (SMILP)" problem, minimizing the total expected cost.

For efficiently utilizing the PV power outputs, the authors in [53] propose an energy management framework comprising of demand and supply side management systems based on ToU pricing. In distribution network, the DSM system controls energy consumption individually through utilizing PV power outputs for reducing residential costs and any inconvenience to residents. The supply side management system works on maintaining the power quality by maximally utilizing the PV power outputs. A DSM approach for smart homes with PV generation is presented in [54]. The approach is implemented using "Clonal Selection Algorithm (CSA)" to provide the optimal day-ahead scheduling of household appliances based on day-ahead dynamic pricing and renewable generation forecasting. Results show that the proposed approaches reduce the electricity consumption cost and reliance on importing energy from the grid.

Energy management of smart homes with renewable resources and an energy storage system (ESS) through optimal scheduling of home appliances for maximizing the consumers' satisfaction level along with minimization of user's energy cost is studied in [55]. Uncertainty associated with renewable energy generation is also considered. Probability theory and quasi-Newton method are used to model the uncertainty and to get the optimal solution.

A DSM program, real-time electricity scheduling (RTES), is proposed in [56] for energy management of smart homes. The proposed approach schedules the smart appliances optimally and improves the usage of integrated renewable energy to reduce the total cost. It also considers the uncertainty in power generated from renewables and subjectivity in energy consumption. The renewable generation is predicted using an effectively designed real-time prediction system. The optimization problem is solved by using genetic algorithm at fixed intervals, and before every optimization calculation, the scheduling system inputs are updated.

A methodology is proposed in [57] aimed at performing DSM for households in smart grid, provided with distributed generation and energy storage systems, through optimization and artificial intelligence (AI) to manage the battery. The research is intended for reducing the electricity cost for consumers. The methodology is validated for any household consumers using ToU rates or specific electricity tariffs such as hourly rate. A DSM method based on robust model predictive control (RMPC) is proposed in [58] for residential smart grids consisting of several interconnected homes (with controllable and noncontrollable loads) and a shared ESS (energy storage system). The presented method focuses on reducing energy bills for users and peak to average ratio while considering possible constraints.

\section{DSM in Systems with EVs}

EVs are gaining immense popularity due to drastic environmental pollution and energy restriction conditions. A recent study shows the hastened development of hybrid and electric vehicles around the globe as illustrated in Figure 6 [59]. 


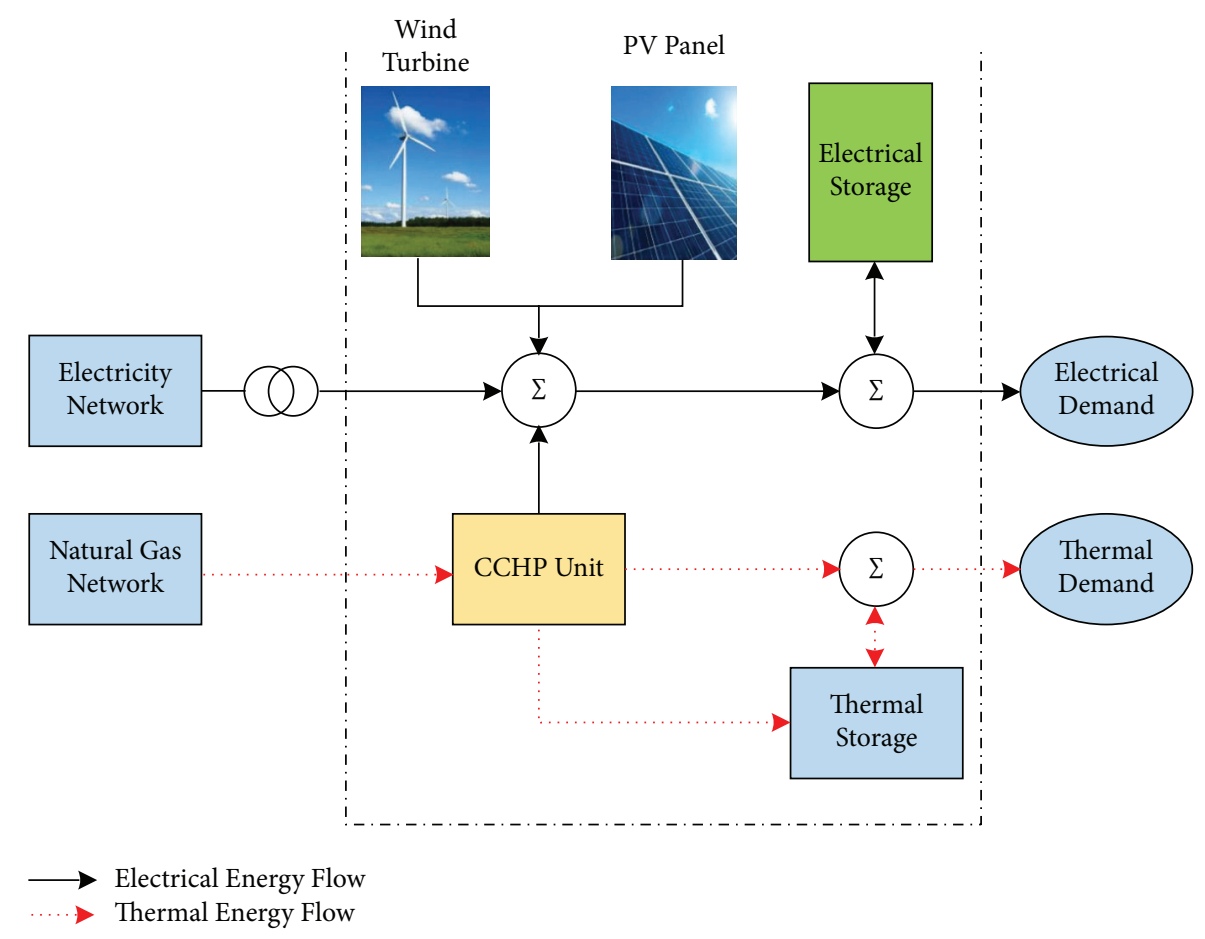

FigURE 5: Schematic of renewable based energy hubs.

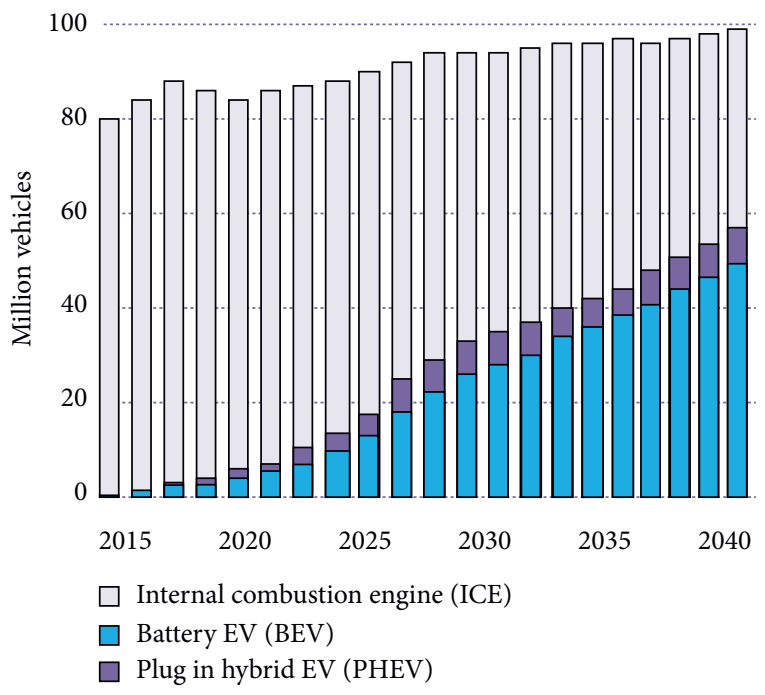

FIGURE 6: Global long-term passenger vehicle scales by drivetrain.

The pros of EVs are stated as the 5 Cs indicated in Figure 7 [60].

Distributed Solar PV generation can be used to overcome energy deficiency in the power system network. The intermittent nature of solar PV generation causes fluctuations in frequency and voltage in power system. Storage plays an important role in this context. EV is used as a DSM tool to reduce the fluctuation in solar PV [61]. Three parameters control the behavior of EV acting as load or source. These three parameters are PV output, State of charge (SOC), and system voltage. To overcome the variable and intermittent nature of solar PV, this paper describes the use

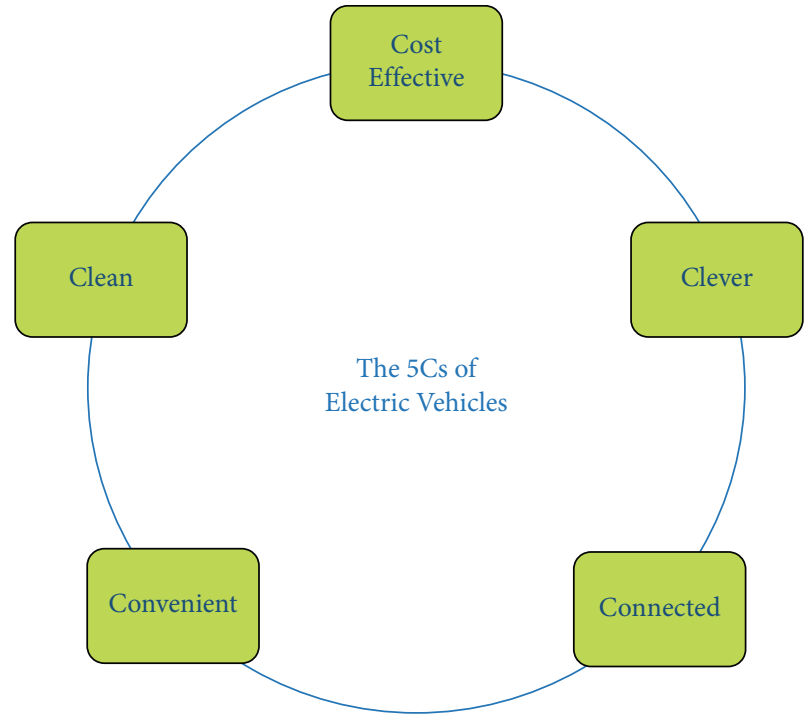

Figure 7: The 5Cs of electric vehicles.

of EVs as source for peak shaving and as load for valley filling. Four different cases are studied considering a $2 \mathrm{MW}$ distributed solar PV generation connected to IEEE 33-bus radial network using MATLAB: high PV generation with EVs, low PV generation with EVs, high PV generation without EVs and low PV generation without EVs. The results showed that conditions of low and high voltages are mitigated, and high energy generation is utilized by incorporating EV as a DSM tool.

EV s connected to the residential loads are considered in [62]. The optimal size of solar PV panel is determined and 
based on the power output of solar PV and day-ahead pricing data; electricity bills of customers are optimized. The optimal problem is formulated and solved using the teacher learner-based optimization (TLBO) algorithm. For analysis, three case studies are considered: normal load, DSM program that optimizes the load, and DSM program that optimizes the load along with PV generation. A comparison based upon per-unit cost is then made between these three case studies. It showed that the system with DSM program and local PV generation is more economical.

Management of EVs and switching power stations is executed in [63] to realize the interaction between EV and switching power stations. Random sampling technique of Monte Carlo is applied to get the charging pattern of batteries for a day. An operational model of charging and switching stations is developed for EV by considering the charging and discharging constraints of charging stations. Interior point optimization technique is used to recognize the orderly charging and discharging pattern of EV.

For day-ahead scheduling of energy consumption of households with plug in electrical vehicles (PEVs), in [64], the residential community is deployed as an agent of native users and charging cost and discharging profit of PEVs are unknown among different communities. A Bayesian game approach is formulated to optimize energy consumption scheduling between different communities. The authors in [65] propose an intelligent charging strategy using machine learning (ML) for making real-time charging decisions for EVs depending on conditions like environment, pricing, driving, and demand times. The purpose of this study is to minimize the overall EV energy cost.

Integrating the EVs in grid results in voltage fluctuations and an increase in cost of deployment of charging setup to meet the peak demand for charging. Demand response schemes can be employed for reduction in cost and peak demand for charging. However, maximizing the charging capacity while minimizing the cost is a perplexing task leading to tripartite game among EV battery service provider, EV owners, and government. This problem is studied as a multiobjective optimization problem in [66]. The optimization problem is described by a battery-swapping cost model, and then "a covariance matrix adaption evolution strategy (CMAES)-based algorithm" is influenced to solve the optimization problem. A control strategy and a DSM program are presented in [67] to incorporate and manage the charging of EVs in a distributed way. An automated fuzzy-based controller is proposed for this purpose that considers voltage at connection point, signal coming from utility, and owners' requirements. A multigroup ToU with critical peaking (MTOUCP) scheme is suggested to avoid the system peaks and the rebound effect. The proposed controller is tested with a new DSM program, and the results showed that it can manage the EV charging fairly, avoid low voltages, and reduce the system peak.

EVs embedded with residential distribution system load present towards distribution systems. Due to frequent charging of EVs in residential areas, the distribution system has to face new load requirements. A DSM strategy has been proposed in [68] to overcome the stress on distribution network presented by EVs. DSM strategy is implemented to avoid most awful power peaks. Two DSM algorithms have been proposed. The proposed DSM algorithms have been grouped into two states. In the first state, both household and EV loads are shifted. In the second state, only EV loads are shifted. The DSM strategies do not manage to charge all the vehicles in the network completely within the 24 hours but reduce the overall load on the transformer and thermal stresses on the conductor.

From the literature reviewed on DSM considering EVs, the most frequently used constraints are

(i) State of charge of EV

(ii) Charging and discharging constraints of PEVs

(iii) Power system constraints

(iv) Power battery constraints

State of charge (SOC) is evaluated from the discharging current and previous state of charge values as given in

$$
\begin{gathered}
\mathrm{SOC}_{t}=\frac{I_{t}^{d}}{U_{n}} \Delta t+\mathrm{SOC}_{t-1}, \\
\mathrm{SOC}_{\min } \leq \mathrm{SOC} \leq \mathrm{SOC}_{\max } .
\end{gathered}
$$

In charging and discharging procedures of plug in electric vehicles, the vehicle cannot be charged and discharged at once. The following equations as given in (12) must be satisfied:

$$
\begin{aligned}
& P_{c, \text { min }} \leq P_{c}(t) \leq P_{c, \text { max }}, \\
& P_{d, \text { min }} \leq P_{d}(t) \leq P_{d, \text { max }} .
\end{aligned}
$$

Power system constraints represent the active and reactive power inserted in node $j$ at time $t$ as shown in

$$
\begin{gathered}
P_{\min } \leq P_{j}(t) \leq P_{\max }, \\
Q_{\min } \leq Q_{j}(t) \leq Q_{\max } .
\end{gathered}
$$

Power battery constraints refer to the requirements that should be met for charging and switching of EV power battery over a day, which are given in the following equation:

$$
\begin{aligned}
& \sum_{t=1}^{24} P_{\mathrm{EV}, j}(t)+U_{j_{0}}=U_{j, \max }, \\
& U_{j, \min } \leq U_{j}(t) \leq U_{j, \max } .
\end{aligned}
$$

\section{Techniques for Implementing DSM Methods}

6.1. Optimization Algorithms. Electricity consumption varies from area to area. It may not be the same for industrial, residential, and commercial areas. The major goal is to achieve balance between power consumption and user comfort. For meeting the rising energy demand, the chief objective is to minimize the energy consumption during peak periods by shifting the loads to non-peak periods. In [69], application of Genetic algorithm (GA), Pigeon Inspired Optimization (PIO), and hybridization of GA and PIO in 
DSM is proposed for residential load management. GA, PIO, and HGP are evaluated on the basis of real-time pricing scheme (RTP) for single home with three different operational time intervals (OTI) and multiple homes with single OTI. Simulations results show that GA, PIO, and HGP can minimize electricity bill and electricity consumption while minimizing the user discomfort. The performance of HGP is better than that of GA and PIO with respect to peak to average ratio, electricity load, and electricity cost for both single home and multiple homes scenarios.

A home energy management (HEM) system using an optimization technique $\mathrm{HBC}$, which is a hybrid of two bioinspired optimization techniques, chicken swarm optimization (CSO) and bacterial foraging optimization (BFO), is proposed in [70] for minimizing peak load and electricity bills. A DSM technique is proposed in [71] to minimize electricity cost and peak to average ratio. To solve the nonconvex problem of appliance scheduling, particle swarm optimization technique is integrated with a game theoretical approach. The optimization problem is modeled taking into consideration the real-world appliances constraints and user perspective constraints. The results showed that the peak to average ratio is reduced more than twice in contrast to convex programming technique.

A generic home energy management control system with energy management control system (EMCS) is introduced in [72], for efficient scheduling of household loads and integrating renewable energy resources into the grid. The EMCS is based on the proposed genetic wind driven optimization (GWDO) along with genetic algorithm (GA), binary particle swarm optimization (BPSO), and wind driven optimization (WDO). Real-time pricing (RTP) scheme and inclined block rate (IBR) are used together for energy pricing. The problem is formulated using multiple knapsack (MK). Two techniques are proposed: energy storage system (ESS) for smoothing the variations in energy generated from renewable resources and trading excess energy between neighbors. An optimization control strategy is proposed in [73] to overcome the shortcomings encountered in current household energy demand management strategy (HEDMS). The proposed strategy minimizes the electricity cost based upon user response, operating power of equipment, and dynamic pricing. Genetic algorithm (GA) based on operating power is used, and the results are compared with loop search optimization algorithm based on rated power.

An energy management controller has been presented in [74] for optimizing energy consumption and DSM. For scheduling the shift able appliances, heuristic optimization algorithms, "BAT inspired and flower pollination," are used, and for scheduling the home appliances, a hybrid optimization algorithm, named "hybrid BAT pollination optimization algorithm (HFBA)," is proposed. Fuzzy logic is developed for controlling the interruptible appliances.

An optimization problem has been formulated in [75] for scheduling the energy consumption of home appliances considering the uncertainty associated with manually operated appliances (MOAs). Worst case scenario is considered for formulating the robust optimization problem considering the real time pricing system linked with inclined block rates to reduce the energy cost. To solve the optimization problem, "an intergeneration projection evolutionary algorithm (IP-EA)" is implemented. Cases based on one-month and one-day periods are studied to verify the effectiveness of the proposed approach.

Table 1 shows the performance comparison of several existing techniques for DSM application.

6.2. Time of Use (ToU) Pricing. In ToU pricing scheme, rates are preset for each time period. It helps both utility and consumers in reducing the overall cost, as rates are high during peak periods and low during non-peak periods. ToU pricing method is extensively used as a DSM technique.

The effect of ToU pricing has been examined in [76] at residential level in developing countries like China. Utilities can render consumers to alter their energy consumption pattern through implementation of ToU pricing scheme to reduce the load demand during peak periods. A framework has been proposed in [77] for decentralized DSM on the distribution network with two type of load demands, residential, and commercial load. Each of these loads has its own renewable generation like rooftop PV and flexible loads. Reduction in electricity bills is observed by formulating an optimal individual scheduling with a compromise between customer convenience and comfort according to ToU pricing.

A home energy management (HEM) system has been proposed in [78]. The proposed system is based on ToU pricing scheme for scheduling the appliances of residential consumers with and without renewable energy sources. The HEM model uses "Evolutionary Algorithms (EAs); (Binary Particle Swarm optimization (BPSO), Genetic Algorithm and Cuckoo search)" to optimally utilize the energy from the grid and renewable energy sources. Cost saving and peak reductions are observed in simulation results.

For minimizing the consumers' electricity bills and peak load demand on residential side, a multiobjective residential DSM with battery storage systems is suggested in [79]. For increasing the number of customers taking part in residential DSM, ToU pricing scheme is used. The problem is formulated as a mixed-integer problem, and "A multiobjective mixed-integer linear programming technique (MOMILP)" is used for solving the problem. Different scenarios are considered for testing the effectiveness of the proposed model. A DSM approach utilizing a smart load control strategy is proposed in [23] for managing the residential load. The impact of ToU pricing scheme on users' preferences is also analyzed.

An energy management system comprising of demand and supply side management based on ToU pricing is proposed in [53] for efficiently utilizing the residential PV output.

6.3. Game Approaches. A trilevel electricity market model comprising of four actors, electricity suppliers for selling electricity, local agents that purchase, sell and utilize electricity, aggregators for buying and selling electricity, and end users for consuming electricity, is proposed in [80]. 
TABle 1: Technoeconomic parameters of the proposed model.

\begin{tabular}{|c|c|c|c|c|c|c|c|c|}
\hline Features & Categories & [69] & {$[70]$} & {$[71]$} & {$[72]$} & [73] & {$[74]$} & [75] \\
\hline Optimization algorithms & $\begin{array}{c}\text { GA } \\
\text { HGP } \\
\text { PIO } \\
\text { HBC } \\
\text { BPSO } \\
\text { PSO } \\
\text { WDO } \\
\text { GWDO } \\
\text { BAT } \\
\text { FP } \\
\text { HFBA } \\
\text { IP-EA }\end{array}$ & $\begin{array}{l}\sqrt{ } \\
\sqrt{ } \\
\sqrt{ }\end{array}$ & $\sqrt{ }$ & $\sqrt{ }$ & $\begin{array}{l}\sqrt{ } \\
\\
\sqrt{ } \\
\sqrt{ } \\
\sqrt{ }\end{array}$ & $\sqrt{ }$ & $\begin{array}{l}\sqrt{ } \\
\sqrt{ } \\
\sqrt{ }\end{array}$ & $\begin{array}{r}\sqrt{ } \\
\sqrt{ } \\
\end{array}$ \\
\hline Pricing schemes & $\begin{array}{c}\text { Real-time pricing } \\
\text { Inclined block rates } \\
\text { Dynamic pricing } \\
\text { Minimize cost } \\
\text { Optimize energy consumption }\end{array}$ & $\begin{array}{l}\sqrt{ } \\
\sqrt{ } \\
\sqrt{ }\end{array}$ & $\sqrt{ }$ & $\sqrt{ }$ & $\begin{array}{l}\sqrt{ } \\
\sqrt{ } \\
\sqrt{ }\end{array}$ & $\begin{array}{l}\sqrt{ } \\
\sqrt{ }\end{array}$ & $\begin{array}{l}\sqrt{ } \\
\sqrt{ }\end{array}$ & $\begin{array}{l}\sqrt{ } \\
\sqrt{ } \\
\sqrt{ }\end{array}$ \\
\hline Optimization objectives & $\begin{array}{l}\text { Maximize user comfort } \\
\text { Peak minimization } \\
\text { Maximize RER utilization } \\
\text { Minimize PAR }\end{array}$ & $\sqrt{ }$ & $\begin{array}{l}\sqrt{ } \\
\sqrt{ }\end{array}$ & $\sqrt{ }$ & $\begin{array}{l}\sqrt{ } \\
\sqrt{ }\end{array}$ & $\begin{array}{l}\sqrt{ } \\
\sqrt{ }\end{array}$ & $\sqrt{ }$ & \\
\hline
\end{tabular}

Interaction between the four actors leads to a trilevel "multileader-multifollower game." For simplicity, the authors solve the problem by a "single-leader-multifollower game" by assuming that the decision variables of one electricity supplier are known, computing the best response of leader. The trilevel DSM problem (TDSM) is formulated as a bilevel problem, and this problem is solved using three different approaches. A Bayesian game approach is used in [64] to optimize the day-ahead energy consumption of households having PEVs considering the incomplete information. In [1], the problem to overcome the peak demand induced by the residential customers in smart grid with multiple energy suppliers is formulated using two noncooperative game approaches.

A real-time decentralized demand side management (RDCDSM) is proposed in [38] to keep the real-time residential load on track with planned day-ahead energy generation by microgrid considering predicted aggregate load demands from customers. The customers deviating from their predictive demand at the time of consumption are charged additional cost or penalty. To avoid penalty, the customers utilize renewable generation, energy storage system, and plan strategies to charge or discharge their EVs.

A game with mixed strategy is used to develop the proposed system. In [81], a multiobjective DSM problem is proposed for residential side demand management based on a cooperative game approach. A compromised solution between two objectives, minimizing consumer's electricity bill and peak load demand, is generated using cooperative game approach based on super-criterion and Pareto-minimum solution. For implementation of the proposed DSM model, ToU pricing scheme is used. The proposed model gives the best compromised solution for different scenarios having different numbers of residential consumers.
In [82], the authors established an improved communication infrastructure based on cognitive radio technology in smart grid to support DSM for scheduling green home energy. An energy storage planning approach based on game algorithm (GA) is proposed. Further, an energy management scheme centered on game theory is developed without leaking user's privacy.

\section{Open Research Issues and Future Directions}

Extensive work has been carried out for the advancement of DSM optimization techniques as depicted in the preceding sections; however, it still has room for much improvement. This section highlights some issues in the current research studies and presents future research directions.

Consumers' resilience from accepting and participating in DSM programs must be overcome, which can be done by developing consumer awareness programs that will persuade consumers to take part in DSM system. Elevated costs of maintaining and installation of control devices must be considered as well. The effect of escalating development of storage systems boosted as a result of inexpensive local storage needs to be addressed.

Thermostatically controlled devices are the major contributors to the increased energy demand. Therefore, there is a great potential to save energy through properly managing these devices. For modeling the thermostatically controlled devices like AC systems, water heaters, and refrigerators, etc., the use of random forests, ensemble trees, and deep learning artificial neural network algorithms can be extended. Machine learning techniques can be used to forecast the accurate load data for achieving energy supply-demand balance [83].

Many studies are centered on data simulation, and diverse data needs to be added for evaluating the effectiveness 
TABLE 2: Nomenclature.

\begin{tabular}{|c|c|c|c|}
\hline Parameters & Symbols & Description & Acronyms \\
\hline Cost & $J$ & Demand side management & DSM \\
\hline Investment cost & $J_{\text {inv }}$ & Electric vehicle & $\mathrm{EV}$ \\
\hline DSM cost & $J_{\mathrm{d} s \mathrm{~m}}$ & Time of use & ToU \\
\hline Power consumption at time $t$ & $P^{t}$ & Demand response & DR \\
\hline Time horizon & $T_{\text {hor }}$ & Renewable energy resource & RER \\
\hline MG operational cost at existing time step $t$ in time horizon & $J_{T_{\text {hor } t}}$ & Distributed energy resource & DER \\
\hline Predictive MG operational cost at step $t+h$ given the information at step $t$ & $\widehat{J}_{T}$ hor,t & Energy storage system & ESS \\
\hline Discount rate & hor,tht & Peak to average ratio & PAR \\
\hline Convenience factor & $\lambda$ & & \\
\hline Priority of user $i$ at time $t$ & $\omega_{i}^{t}$ & & \\
\hline Charging and switching of the electric vehicle power battery at node $j$ at time $t$ & $P_{\mathrm{EV}, j}(t)$ & & \\
\hline Total capacity of batteries participating in charging and switching over a day & $U_{j, \max }$ & & \\
\hline Power of the power battery of node $j$ over a day at time $t$ & $U_{j}(t)$ & & \\
\hline Discharging power of plug in EV at time $t$ & $P_{d}^{\prime}(t)$ & & \\
\hline Discharging current & $I_{t}^{d}$ & & \\
\hline Reactive power at time $t$ & $Q(t)$ & & \\
\hline Cost for residential customer & $J_{\text {Res }}$ & & \\
\hline Operation cost & $J_{\text {op }}$ & & \\
\hline Carbon emission cost & $J_{\text {carbon }}$ & & \\
\hline Residential power consumption & $P_{\text {Res }}$ & & \\
\hline MG operational cost in time horizon & $J_{T_{h o r}}^{\text {Kes }}$ & & \\
\hline ToU tariff at time slot $t$ & $C_{\mathrm{ToU}}^{t}$ & & \\
\hline Discount factor & $\gamma$ & & \\
\hline Convenience level & $C$ & & \\
\hline Cost constraint at time $t$ & $C_{p}^{t}$ & & \\
\hline Frequency deviation & $\Delta f$ & & \\
\hline Charge in the power battery of an electric vehicle before charging of node $j$ & $U_{j_{0}}$ & & \\
\hline Min total capacity of batteries participating in charging within a specified day & $U_{j, \min }^{j 0}$ & & \\
\hline Charging power of plug in EV at time $t$ & $P_{c}(t)$ & & \\
\hline Nominal capacity & $U_{n}$ & & \\
\hline Active power at time $t$ & $P(t)$ & & \\
\hline
\end{tabular}

of these studies in realistic scenarios. The studies show that if specific set points are not included in the simulation data, they will not able to forecast the demand precisely in those operating circumstances. DSM for residential consumers can be applied in a real-world environment, and realistic data considering consumer's habits can be predicted by including real consumers. The coordination among consumers in real-time frameworks needs to be centered keeping the consumers privacy intact. Sensor network applications can be endorsed for optimizing energy usage in smart cities and intelligent buildings. DSM algorithms can be exploited in blockchain based distribution networks.

An essential component of the DSM problem is the collaboration approach of several devices [84-86]. It can provide improved power distribution, stability, and reduced circulating currents. Further research can be done on this matter.

Market equilibriums can be considered instead of Nash equilibriums in multilevel models for DSM pricing for a more realistic perspective. The energy transaction in market equilibrium is based on bargaining between the supplier and the buyer.

\section{Conclusion}

The rejuvenation of power infrastructure enables the execution of demand side management programs for energy management throughout the world. In this paper, realization of various DSM techniques on a variety of load including residential, industrial, and commercial is looked upon. The performance of DSM strategies utilizing various optimization techniques, including Evolutionary algorithms, Heuristic algorithms, Pricing schemes, and Game approaches, is analyzed. Moreover, the impact of DSM on systems with integrated renewable energy resources, distributed energy resources, storage devices, and EVs is studied. Table 2.

\section{Data Availability}

No data were used to support this study.

\section{Conflicts of Interest}

The authors declare that they have no conflicts of interest.

\section{Acknowledgments}

This work was supported in part by the Brain Pool (BP) Program funded by the Ministry of Science and ICT through the National Research Foundation of Korea under Grant 2019H1D3A1A01102988, and in part by the Basic Science Research Program through the National Research Foundation of Korea funded by the Ministry of Education under Grant 2016R1D1A1B01008058. 


\section{References}

[1] M. Majid Jalali and A. Kazemi, "Demand side management in a smart grid with multiple electricity suppliers," Energy, vol. 81, pp. 766-776, 2015.

[2] D. Li, W.-Y. Chiu, H. Sun, and H. Vincent Poor, "Multiobjective optimization for demand side management program in smart grid," IEEE Transactions on Industrial Informatics, vol. 14, no. 4, pp. 1482-1490, 2017.

[3] H. Cai, S. Shen, Q. Lin, X. Li, and H. Xiao, "Predicting the energy consumption of residential buildings for regional electricity supply-side and demand-side management," IEEE Access, vol. 7, pp. 30386-30397, 2019.

[4] H. Martin, Z. De Grève, and F. Vallée, "Cooperative demandside management scenario for the low-voltage network in liberalised electricity markets," IET Generation, Transmission \& Distribution, vol. 12, no. 22, pp. 5990-5999, 2018.

[5] M. Latifi, A. Khalili, A. Rastegarnia, W. M. Bazzi, and S. Sanei, "Demand-side management for smart grid via diffusion adaptation," IET Smart Grid, vol. 3, no. 1, pp. 69-82, 2020.

[6] I. A. Adejumobi and J. A. Adeoti, "Efficient utilization of industrial power: demand side management approach," in Proceedings of the 2019 IEEE PES/IAS PowerAfrica, August 2019.

[7] J. Teh, Y.-H. Cheng, and C.-M. Lai, "Impact of demand side management and dynamic thermal rating system on the reliability of power systems," in Proceedings of the 2018 International Symposium on Computer, Consumer and Control (IS3C), December 2018.

[8] L. Zhao, Y. Zhou, F. L. Quilumba, and W.-J. Lee, "Potential of the commercial sector to participate in the demand side management program," IEEE Transactions on Industry Applications, vol. 55, no. 6, pp. 7261-7269, 2019.

[9] Z. A. Khan and D. Jayaweera, "Smart meter data based load forecasting and demand side management in distribution networks with embedded PV systems," IEEE Access, vol. 8, pp. 2631-2644, 2019.

[10] S. A. T. Carvalho, C. S. Marismar, and C. A. Siebra, "Demandside management of hierarchical energy distribution based on a joint intention protocol," in Proceedings of the 2018 Simposio Brasileiro de Sistemas Eletricos (SBSE), May 2018.

[11] Z. Bao, W. Qiu, L. Wu et al., "Optimal multi-timescale demand side scheduling considering dynamic scenarios of electricity demand," IEEE Transactions on Smart Grid, vol. 10, no. 3, pp. 2428-2439, 2018.

[12] Z. Baharlouei, H. Narimani, and M. Hashemi, "On the convergence properties of autonomous demand side management algorithms," IEEE Transactions on Smart Grid, vol. 9, no. 6, pp. 6713-6720, 2017.

[13] A. H. Abid and A. Hasan, "An approach for demand side management of non-flexible load in academic buildings," in Proceedings of the 2018 15th International Conference on Smart Cities: Improving Quality of Life Using ICT \& IoT (HONET-ICT), October 2018.

[14] I. Khan, "Energy-saving behaviour as a demand-side management strategy in the developing world: the case of Bangladesh," International Journal of Energy and Environmental Engineering, vol. 10, no. 4, pp. 493-510, 2019.

[15] C.-S. Tai, J.-H. Hong, and L.-C. Fu, "A real-time demand-side management system considering user behavior using deep Q-Learning in home area network," in Proceedings of the 2019 IEEE International Conference on Systems, Man and Cybernetics (SMC), October 2019.
[16] K. Ma, Y. Yu, B. Yang, and J. Yang, "Demand-side energy management considering price oscillations for residential building heating and ventilation systems," IEEE Transactions on Industrial Informatics, vol. 15, no. 8, pp. 4742-4752, 2019.

[17] L. Tan, Y. Xiao, and L. Song, "Deep reinforcement Learning based residential demand side management with edge computing," in Proceedings of the 2019 IEEE International Conference on Communications, Control, and Computing Technologies for Smart Grids (SmartGridComm), October 2019.

[18] N. T. Gopal, S. N. V. S. K. Chaitanya, B. V. Rao, and S. K. Sameer Saheb, "Demand side management of energy efficient street lighting system through CCMS," in Proceedings of the 2018 3rd IEEE International Conference on Recent Trends in Electronics, Information \& Communication Technology (RTEICT), May 2018.

[19] M. Glavan, D. Gradišar, I. Humar, and D. Vrančić, "Refrigeration control algorithm for managing supermarket's overall peak power demand," IEEE Transactions on Control Systems Technology, vol. 27, no. 5, pp. 2279-2286, 2018.

[20] V. A. Rabl and C. W. Gellings, "The concept of demand-side management," in Demand-Side Management and Electricity End-Use Efficiency, pp. 99-112, Springer, Berlin, Germany, 1988.

[21] R. N. El idrissi, M. Ouassaid, and M. Maaroufi, "Demand side management strategy by optimal day-ahead Load shifting in smart grid," in Proceedings of the 2018 6th International Renewable and Sustainable Energy Conference (IRSEC), December 2018 .

[22] D. P. Bertineti, L. N. Canha, A. P. Medeiros, R. M. De Azevedo, and B. F. Da Silva, "Heuristic scheduling algorithm for load shift DSM strategy in smart grids and IoT scenarios," in Proceedings of the 2019 IEEE PES Innovative Smart Grid Technologies Conference-Latin America (ISGT Latin America), September 2019.

[23] R. Mehta, P. Verma, and D. Srinivasan, "Smart load control strategy for residential demand side management," in Proceedings of the 2018 IEEE Innovative Smart Grid TechnologiesAsia (ISGT Asia), May 2018.

[24] L. Barbierato, L. Bottaccioli, E. Macii, E. Grasso, A. Acquaviva, and E. Patti, "A distributed software solution for demand side management with consumer habits prediction," in Proceedings of the 2019 IEEE International Conference on Environment and Electrical Engineering and 2019 IEEE Industrial and Commercial Power Systems Europe (EEEIC/I\&CPS Europe), July 2019.

[25] G. R. Hemanth, S. Suganya, and P. Venkatesh, "Neural network based demand side management using load shifting," in Proceedings of the 2018 National power engineering conference (NPEC), March 2018.

[26] N. Blaauwbroek, R. Bosch, P. Nguyen, and S. Han, "Three-phase grid supportive demand side management with appliance flexibility modelling," in Proceedings of the 2018 IEEE International Conference on Environment and Electrical Engineering and 2018 IEEE Industrial and Commercial Power Systems Europe (EEEIC/IઐCPS Europe), June 2018.

[27] H. Swalehe and B. Marungsri, "Intelligent algorithm for optimal load management in smart home appliance scheduling in distribution system," in Proceedings of the 2018 International Electrical Engineering Congress (iEECON), March 2018.

[28] M. Praveen and G. V. S. Rao, "Ensuring the reduction in peak load demands based on load shifting DSM strategy for smart 
grid applications," Procedia Computer Science, vol. 167, pp. 2599-2605, 2020.

[29] P. Malik, S. Garg, K. Singhal et al., "Demand side management using GUI," in Proceedings of the 2019 3rd International Conference on Recent Developments in Control, Automation \& Power Engineering ( $R D$-CAPE), October 2019.

[30] A. Khalid, N. Javaid, M. Guizani, M. Alhussein, K. Aurangzeb, and M. Ilahi, "Towards dynamic coordination among home appliances using multi-objective energy optimization for demand side management in smart buildings," IEEE Access, vol. 6, pp. 19509-19529, 2018.

[31] Niharika and V. Mukherjee, "Day-ahead demand side management using symbiotic organisms search algorithm," IET Generation, Transmission \& Distribution, vol. 12, no. 14, pp. 3487-3494, 2018.

[32] E. Guelpa and L. Marincioni, "Demand side management in district heating systems by innovative control," Energy, vol. 188, p. 116037, 2019.

[33] M. Uddin, M. F. Romlie, M. F. Abdullah, M. F. Abdullah et al., "A review on peak load shaving strategies," Renewable and Sustainable Energy Reviews, vol. 82, pp. 3323-3332, 2018.

[34] H. Fan, J. Lu, Z. Li, M. Shahidehpour, and S. Zhang, "Optimal planning of integrated electricity-gas system with demand side management," IEEE Access, vol. 7, pp. 176790-176798, 2019.

[35] S. Zou, Z. Ma, G. Zhu, and X. Liu, "Demand side management in direct current distribution networks: convergence and optimality," in Proceedings of the 2018 IEEE International Symposium on Circuits and Systems (ISCAS), May 2018.

[36] S. Favuzza, F. Massaro, R. Musca et al., "Effects of demand side management on the operation of an isolated lv microgrids," in Proceedings of the 2019 IEEE International Conference on Environment and Electrical Engineering and 2019 IEEE Industrial and Commercial Power Systems Europe (EEEIC/I \& CPS Europe), June 2019.

[37] X. Yang, Y. Zhang, H. He, S. Ren, and G. Weng, "Real-time demand side management for a microgrid considering uncertainties," IEEE Transactions on Smart Grid, vol. 10, no. 3, pp. 3401-3414, 2018.

[38] M. H. K. Tushar, A. W. Zeineddine, and C. Assi, "Demandside management by regulating charging and discharging of the EV, ESS, and utilizing renewable energy," IEEE Transactions on Industrial Informatics, vol. 14, no. 1, pp. 117-126, 2017.

[39] M. Aisha, M. Hebatallah, R. Syed, R. Belkacemi, F. Awwad, and O. Hasan, "A utility maximized demand-side management for autonomous microgrid," in Proceedings of the 2018 IEEE Electrical Power and Energy Conference (EPEC), October 2018.

[40] M. Aniket, V. P. Dhote, and A. G. Thosar, "Demand side management and voltage regulation in microgrid using electric spring," in Proceedings of the 2018 International Conference on Emerging Trends and Innovations In Engineering And Technological Research (ICETIETR), July 2018.

[41] M. Babaei and M. T. H. Beheshti, "Demand side management of a stand-alone hybrid power grid by using fuzzy type-2 logic control," in Proceedings of the 2018 Smart Grid Conference (SGC), November 2018.

[42] G. Das and D. C. Das, "Demand side management for active power control of autonomous hybrid power system," in Proceedings of the 2018 2nd International Conference on Power, Energy and Environment: Towards Smart Technology (ICEPE), June 2018.
[43] H. Abd ul Muqeet, H. M. Munir, A. Ahmad, I. Ali Sajjad, G.-J. Jiang, and H.-X. Chen, "Optimal operation of the campus microgrid considering the resource uncertainty and demand response schemes," Mathematical Problems in Engineering, vol. 2021, Article ID 5569701, , 2021.

[44] P. U. Herath, V. Fusco, M. Navarro Cáceres et al., "Computational intelligence-based demand response management in a microgrid," IEEE Transactions on Industry Applications, vol. 55, no. 1, pp. 732-740, 2018.

[45] N. Mohan, T. P. Imthias Ahamed, and J. M. Johnson, "Demand side management for a household using resource scheduling," in Proceedings of the 2018 International CET Conference on Control, Communication, and Computing (IC4), July 2018.

[46] J. Ehnberg and M. Anders, "Increased value of demand side management by reshaping the Load duration curve with wind and solar power," in Proceedings of the 2019 IEEE PES Innovative Smart Grid Technologies Europe (ISGT-Europe), September 2019.

[47] A. Soares, Á. Gomes, C. H. Antunes, and C. Oliveira, "A customized evolutionary algorithm for multiobjective management of residential energy resources," IEEE Transactions on Industrial Informatics, vol. 13, no. 2, pp. 492-501, 2016.

[48] M. Di Somma, G. Graditi, E. Heydarian-Forushani, M. Shafie-Khah, and P. Siano, "Stochastic optimal scheduling of distributed energy resources with renewables considering economic and environmental aspects," Renewable Energy, vol. 116, pp. 272-287, 2018.

[49] M. Daneshvar, B. Mohammadi-Ivatloo, S. Asadi, K. Zare, and A. Anvari-Moghaddam, "Optimal day-ahead scheduling of the renewable based energy hubs considering demand side energy management," in Proceedings of the 2019 International conference on Smart Energy Systems and Technologies (SEST), September 2019.

[50] T. Li and M. Dong, "Real-time residential-side joint energy storage management and load scheduling with renewable integration," IEEE Transactions on Smart Grid, vol. 9, no. 1, pp. 283-298, 2016.

[51] F. Elghitani and E. El-Saadany, "Smoothing net load demand variations using residential demand management," IEEE Transactions on industrial informatics, vol. 15, no. 1, pp. 390-398, 2018.

[52] M. Bohlayer, M. Fleschutz, M. Braun, and G. Zöttl, “Demand side management and the participation in consecutive energy markets-a multistage stochastic optimization approach," in Proceedings of the 2018 15th International Conference on the European Energy Market (EEM), June 2018.

[53] Y. Fujimoto, H. Kikusato, S. Yoshizawa et al., "Distributed energy management for comprehensive utilization of residential photovoltaic outputs," IEEE Transactions on Smart Grid, vol. 9, no. 2, pp. 1216-1227, 2016.

[54] S. H. Elyas, H. Sadeghian, O. A. Hayder, and Z. Wang, "Optimized household demand management with local solar PV generation," in Proceedings of the 2017 North American Power Symposium (NAPS), September 2017.

[55] Z. Xu, Y. Gao, M. Hussain, and P. Cheng, "Demand side management for smart grid based on smart home appliances with renewable energy sources and an energy storage system," Mathematical Problems in Engineering, vol. 2020, Article ID 9545439, , 2020.

[56] S. Li, J. Yang, W. Song, and A. Chen, "A real-time electricity scheduling for residential home energy management," IEEE Internet of Things Journal, vol. 6, no. 2, pp. 2602-2611, 2018. 
[57] K. G. Di Santo, S. G. Di Santo, R. M. Monaro, and M. A. Saidel, "Active demand side management for households in smart grids using optimization and artificial intelligence," Measurement, vol. 115, pp. 152-161, 2018.

[58] S. M. Hosseini, R. Carli, and M. Dotoli, "A residential demand-side management strategy under nonlinear pricing based on robust model predictive control," in Proceedings of the 2019 IEEE International Conference on Systems, Man and Cybernetics (SMC), IEEE, Bari, Italy, October 2019.

[59] M. Agrawal and M. Sufiyan Rajapatel, "Global perspective on electric vehicle 2020," International Journal of Engineering and Technical Research, vol. 9, no. 1, 2020.

[60] C. Maini, K. Gopal, and R. Prakash, "Making of an "all reason"electric vehicle," in Proceedings of the 2013 World Electric Vehicle Symposium and Exhibition (EVS27), November 2013.

[61] Q. Ali, H. Z. Butt, and S. A. A. Kazmi, "Integration of electric vehicles as smart loads for demand side management in medium voltage distribution network," in Proceedings of the 2018 International Conference on Computing, Electronic and Electrical Engineering (ICE Cube), November 2018.

[62] U. Akram and M. Khalid, "Residential demand side management in smart grid paradigm," in Proceedings of the 2018 IEEE PES Asia-Pacific Power and Energy Engineering Conference (APPEEC), October 2018.

[63] H. Gan and C. Zheng, "Operation optimization of electric vehicle based on demand side management," in Proceedings of the 2019 34rd Youth Academic Annual Conference of Chinese Association of Automation (YAC), June 2019.

[64] X. Liu, B. Gao, C. Wu, and Y. Tang, "Demand-side management with household plug-in electric vehicles: a Bayesian game-theoretic approach," IEEE Systems Journal, vol. 12, no. 3, pp. 2894-2904, 2017.

[65] K. L. López, C. Gagné, and M.-A. Gardner, "Demand-side management using deep learning for smart charging of electric vehicles," IEEE Transactions on Smart Grid, vol. 10, no. 3, pp. 2683-2691, 2018.

[66] L. Zhang, S. Zhou, J. An, and Q. Kang, "Demand-side management optimization in electric vehicles battery swapping service," IEEE Access, vol. 7, pp. 95224-95232, 2019.

[67] S. Faddel and O. A. Mohammed, "Automated distributed electric vehicle controller for residential demand side management," IEEE Transactions on Industry Applications, vol. 55, no. 1, pp. 16-25, 2018.

[68] J. Badugu, Y. P. Obulesu, and C. S. Babu, "Development of demand side management strategy for smart residential distribution system embedded with EV load," in Proceedings of the TENCON 2019-2019 IEEE Region 10 Conference (TENCON), October 2019.

[69] M. H. A. Rehman, N. Javaid, M. N. Iqbal et al., "Demand side management using hybrid genetic algorithm and pigeon inspired optimization techniques," in Proceedings of the 2018 IEEE 32nd International Conference on Advanced Information Networking and Applications (AINA), May 2018.

[70] Z. Abbas, N. Javaid, J. Ahmad, M. H. A. Rehman, J. Sahi, and A. Saboor, "Demand side energy management using hybrid chicken swarm and bacterial foraging optimization techniques," in Proceedings of the 2018 IEEE 32nd International Conference on Advanced Information Networking and Applications (AINA), May 2018.

[71] F. Viani and M. Salucci, "A user perspective optimization scheme for demand-side energy management," IEEE Systems Journal, vol. 12, no. 4, pp. 3857-3860, 2017.
[72] N. Javaid, G. Hafeez, S. Iqbal, N. Alrajeh et al., "Energy efficient integration of renewable energy sources in the smart grid for demand side management," IEEE Access, vol. 6, pp. 77077-77096, 2018.

[73] X. Jiang and C. Xiao, "Household energy demand management strategy based on operating power by genetic algorithm," IEEE Access, vol. 7, pp. 96414-96423, 2019.

[74] R. Khalid, N. Javaid, M. H. Rahim, S. Aslam, and A. Sher, "Fuzzy energy management controller and scheduler for smart homes," Sustainable Computing: Informatics and Systems, vol. 21, pp. 103-118, 2019.

[75] Y. F. Du, L. Jiang, Y. Li, and Q. Wu, “A robust optimization approach for demand side scheduling considering uncertainty of manually operated appliances," IEEE Transactions on Smart Grid, vol. 9, no. 2, pp. 743-755, 2016.

[76] L. Zhao, Z. Yang, and W.-J. Lee, "The impact of time-of-use (TOU) rate structure on consumption patterns of the residential customers," IEEE Transactions on Industry Applications, vol. 53, no. 6, pp. 5130-5138, 2017.

[77] O. A. Hayder, H. Sadeghian, and Z. Wang, "Decentralized demand side management optimization for residential and commercial load," in Proceedings of the 2018 IEEE International Conference on Electro/Information Technology (EIT), May 2018.

[78] N. Javaid, I. Ullah, M. Akbar et al., “An intelligent load management system with renewable energy integration for smart homes," IEEE access, vol. 5, pp. 13587-13600, 2017.

[79] B. Lokeshgupta and S. Sivasubramani, "Multi-objective home energy management with battery energy storage systems," Sustainable Cities and Society, vol. 47, Article ID 101458, 2019.

[80] D. Aussel, L. Brotcorne, S. Lepaul, and L. von Niederhäusern, "A trilevel model for best response in energy demand-side management," European Journal of Operational Research, vol. 281, no. 2, pp. 299-315, 2020.

[81] B. Lokeshgupta and S. Sivasubramani, "Multi-objective residential demand side management with game theory approach," in Proceedings of the 2018 20th National Power Systems Conference (NPSC), pp. 1-6, IEEE, Tiruchirappalli, India, December 2018.

[82] K. Wang, H. Li, S. Maharjan, Y. Zhang, and S. Guo, "Green energy scheduling for demand side management in the smart grid," IEEE Transactions on Green Communications and Networking, vol. 2, no. 2, pp. 596-611, 2018.

[83] R. Bhattacharyya and A. Bhattacharyya, "Smart grid demandside management by machine Learning," in Proceedings of the Global AI Congress 2019, J. Mandal and S. Mukhopadhyay, Eds., vol. 1112SingaporeSpringer, 2020 Advances in Intelligent Systems and Computing.

[84] Q. Sun, R. Han, H. Zhang, J. Zhou, and J. M. Guerrero, “A multiagent-based consensus algorithm for distributed coordinated control of distributed generators in the energy internet," IEEE Transactions on Smart Grid, vol. 6, no. 6, pp. 3006-3019, 2015.

[85] M. Y. Mehmood, A. Oad, M. Abrar et al., "Edge computing for IoT-enabled smart grid," Security and Communication Networks, vol. 2021, Article ID 5524025, , 2021.

[86] R. Wang, Q. Sun, W. Hu, Y. Li, D. Ma, and P. Wang, "SoCbased droop coefficients stability region analysis of the battery for stand-alone supply systems with constant power loads," IEEE Transactions on Power Electronics, vol. 36, no. 7, pp. 7866-7879, 2021. 